\title{
Activated Lymphocytes Secretome Inhibits Differentiation and Induces Proliferation of C2C12 Myoblasts
}

\author{
Nasser Al-Shantia Peter Durcan ${ }^{b}$ Sarah Al-Dabbagh ${ }^{a}$ Georgi A. Dimchev \\ Claire E. Stewart ${ }^{d}$ \\ a'Work was performed in: Institute for Biomedical Research into Human Movement and Health (IRM), \\ Manchester Metropolitan University, Faculty of Science and Engineering, John Dalton Building, \\ Manchester, UK; ' Department of Physiological Sciences, Stellenbosch University, Stellenbosch, South \\ Africa; 'Present address: Institute of Genetics, University of Bonn, Bonn, Germany; ${ }^{d P r e s e n t ~ a d d r e s s: ~}$ \\ Research Institute for Sport \& Exercise Sciences, School of Sport and Exercise Sciences, Tom Reilly \\ Building, Byrom Street Campus, Liverpool John Moores University, Liverpool, UK
}

\section{Key Words}

Myoblasts • Proliferation • Differentiation • Immune system • Lymphocytes • Secretome

\begin{abstract}
Background/Aims: ageing is associated with a marked decline in immune function which may contribute to the local environment that can influence the regenerative process of skeletal muscle cells. Methods: Herein, we focused on determining the effect of an activated immune system secretome on myoblast differentiation and proliferation as possible means to attenuate adverse effects of muscle aging. C2C12 myoblasts were used as model to assess the impact of lymphocyte conditioned media (CM) following anti-CD3/IL-2 activation. Results: Myoblasts cultured with activated lymphocytes CM exhibited reduced morphological and biochemical differentiation $(98 \pm 20, p<0.005)$ and increased entry to the $S$ Phase of the cell cycle $(61 \% \pm 7, p<0.001)$, when compared with myoblasts cultured with non-activated lymphocytes CM. Associated with increased proliferation and reduced differentiation, muscle specific transcription factors MyoD and myogenin were significantly reduced in $\mathrm{C} 2 \mathrm{C} 12$ treated with activated lymphocytes CM vs control CM, respectively (myoD: $0.5 \pm 0.12$ fold reduction $\mathrm{P}<0.005)$; myogenin: $0.38 \pm 0.08$ fold reduction; $\mathrm{p}<0.005)$. Moreover, key protein of proliferation $\mathrm{pERK} 1 / 2$ increased $(46 \pm 11 \mathrm{U} / \mathrm{ml}, \mathrm{p}<0.05)$ whereas mediator of differentiation pAkt decreased $(21 \pm 12 \mathrm{U} / \mathrm{ml}, \mathrm{p}<0.05)$ in $\mathrm{C} 2 \mathrm{C} 12$ treated with activated vs. non-activated CM. Conclusion: our data demonstrate that, following activation, secretome of the immune system cells elicit marked regulatory effects on skeletal muscle growth and differentiation; enhancing the former with the loss of the latter.
\end{abstract}

Copyright @ 2014 S. Karger AG, Basel 


\section{Introduction}

Skeletal muscle is an essential peripheral metabolically active tissue, comprising $\sim 40$ $50 \%$ of the healthy human body mass [1]. Muscle wasting, is a significant public health problem that can occur as a consequence of many diseases including: muscular dystrophies, cardiovascular disease, diabetes or cancer cachexia (which alone is responsible for $\sim 30 \%$ of all cancer deaths). Ageing is also associated with a progressive loss of muscle mass (sarcopenia) leading to loss of functional independence [2]. Regardless of the cause, progressive loss of muscle mass culminates in increased frailty, weakness and loss of independence, impaired quality of life and ultimately results in increased morbidity and mortality. Similarly, in ageing there is marked decline in immunity which is considered a significant contributor to disease burden. This decrease in immunity is mainly associated with alterations in T cell activity [3]. Recently, a few studies have revealed that there are complex interactions between skeletal muscle and the immune system that regulate the regenerative capacity of muscle [4]. The immune system responds to muscle damage with a complex sequence of reactions, which ultimately lead to inflammation followed by muscle regeneration. This inflammatory response contains the damage in the muscle by cleaning up cellular debris and subsequently repairing the damaged area [5]. Macrophages trigger damaged muscle repair through secretion of proteins, which are responsible for cell-to-cell contact, and for recruiting lymphocytes to the injured muscle site. Activated lymphocytes ultimately activate satellite cells, the first step in the physical repair of damaged muscle [6, 7]. Macrophages, the second responders to muscle damage after neutrophils, continue to increase in number until approximately $48 \mathrm{~h}$ postinjury, when they begin to decline sharply. In rodent models, this decline is associated with an increase in numbers of activated lymphocytes, which remain significantly elevated for 10 days of regeneration [8-10]. This early, yet long lasting infiltration of activated lymphocytes may impact significantly on skeletal muscle proliferation, differentiation and repair.

Although, it is well established that lymphocyte concentrations (CD4 and CD8 T cells) are increased in blood and muscle after the exercise $[6,11]$, very little is known about the specific role of T lymphocytes in skeletal muscle growth, survival and differentiation. However, activated lymphocytes simultaneously secrete numerous growth factors and interleukins (Transforming growth factor- $\beta$, IL-10, IL-4, IL-6 and IL-7), which may contribute to the early inflammatory stages that precede muscle regeneration $[12,13]$. One study, using scid/ $m d x$ ( $m d x$ : dystrophic mouse, scid: immunodeficient mouse) as model to examine possible interactions between skeletal muscle and T cells, demonstrated that these mice exhibited reduced muscle fibrosis and degeneration [14]. Recently, Dumke and Lees investigated the influence of activated T lymphocytes on the regeneration capacity of muscle precursor cells [15]. In this study, rat satellite cells were isolated from the gastrocnemius and plantaris muscles of 3 and 32 month old animals and were cultured with splenic activated T cells. It was shown that IL-2 activated T lymphocytes induced proliferation and migration of muscle precursor cells. An additional recent study reported that supernatants of cultured anti-CD3 activated murine TH (T helper) lymphocytes induced the contraction of human bronchial smooth muscle cells [16].

Therefore, taken together these studies led us to hypothesise that secreted proteins (cytokines, growth factors) from anti-CD3 activated immune system may improve skeletal muscle functions. This hypothesis was challenged by the following objectives 1) to investigate the impact of secretome of activated-human lymphocytes on skeletal muscle cell differentiation and proliferation, 2) to determine the key myogenic regulatory factors, which may be altered by said incubations 3 ) to identify the signalling pathways that could be triggered by secreted cytokines. To enable us to challenge our hypothesis and carry out our objectives, C2C12, murine myoblasts derived from satellite cells, whose behaviour corresponds to that of progenitor lineage were used as model system. Herein, we reported that CM of anti-CD3 activated lymphocytes induced proliferation and inhibited differentiation of skeletal muscle cells. These findings were further investigated where induced proliferation was associated with low creatine kinase (CK) activity, high cell count 
and elevated S-phase entry. Furthermore, MyoD and myogenin expression was obviously decreased in proliferating cells whereas pERK1/2 was significantly increased and Akt was markedly decreased.

\section{Materials and Methods}

Isolation and Culture of human lymphocytes

Following in house ethical approval (MMU) and informed consent, human lymphocytes were isolated from donated blood of healthy individuals ( $n=9,3$ females and 6 males, age between 20-25 years old) using methods as described previously [17]. Blood $(20 \mathrm{ml})$ was carefully layered on the same volume of FicollPaque PLUS (GE Healthcare Life Sciences, Buckinghamshire, UK). After 40 minutes centrifugation at $400 \times \mathrm{g}$ at $18-20^{\circ} \mathrm{C}$, the lymphocyte layer was carefully removed and washed twice with RPMI-1640 media. Isolated lymphocytes (3x105/well) were cultured in pre-coated flat-bottomed microwell plates with anti-CD3 (OKT3, $10 \mu \mathrm{g} / \mathrm{ml}$, Cilag AG, Schaffhausen, Switzerland), as previously described [18]. Cells were grown in RPMI1640 medium, supplemented with $10 \%(\mathrm{v} / \mathrm{v})$ human $\mathrm{AB}$ serum and $1 \%$ penicillin/streptomycin at $37^{\circ} \mathrm{C}$ in $5 \% \mathrm{CO}_{2}$. All cultures, including negative controls (e.g. in the absence of anti-CD3) were supplemented with $50 \mathrm{U} / \mathrm{ml}$ human recombinant interleukin-2 (IL-2) (R\&D Systems Abingdon, UK).

\section{Recovery of secreted cytokines}

To recover and purify secreted cytokines (most of cytokines are relatively low-molecular weight between $8-25 \mathrm{KDa}$ ), [19] from activated T-lymphocytes in the supernatant of culture media, an Amicon® Ultra-4 Centrifugal Filter device was used (Millipore, Watford, UK). This device filters and purifies any protein found in tissue culture, which are larger than $3 \mathrm{KDa}$. After 4 days in culture, lymphocytes supernatants were collected and filtered as manufacture described. Briefly, $4 \mathrm{ml}$ of tissue culture conditioned media were collected from each treatment group and were centrifuged in an Ultracel-3 Membrane tube for $30 \mathrm{~min}$ at $5000 \mathrm{xg}$.

\section{Conditioned Media (CM) Preparation}

The remaining concentrate of secreted cytokines $(200 \mu \mathrm{l})$ was mixed with $3.8 \mathrm{ml}$ of differentiation medium (DM), composed of (2\% horse serum, DMEM media, 1\% Pen-strep and 200mM L-glutamine) to make the CM. Three different types of CM were prepared. CM1, contained concentrate filtered from RPMI-1640 media only supplemented with IL-2 and incubated in anti-CD3 coated wells in the absence of lymphocytes (negative control treatment). This control was included to exclude any effect of the $10 \%$ of Human AB serum (this serum is normally added to RPMI- 1640 which is used to lymphocytes culture)' IL-2 or anti-CD3 on myoblast behaviour. CM2 contained concentrate obtained from lymphocytes cultured with IL-2 but without anti-CD3 (non-activated control treatment, Fig. 1). CM3 contained concentrate obtained from lymphocytes cultured with both anti-CD3 and IL-2 (test treatment, Fig. 1).

Fig. 1. Images of activated vs. non-activated lymphocytes Representative photographs of lymphocytes cultured without (CM2) and with anti-CD3 (CM3) for 4 days in RPMI1640 meida supplement with $50 \mathrm{U} / \mathrm{ml}$ of hrIL-2. Activated lymphocytes were morphologically changed (activated T cells exhibited

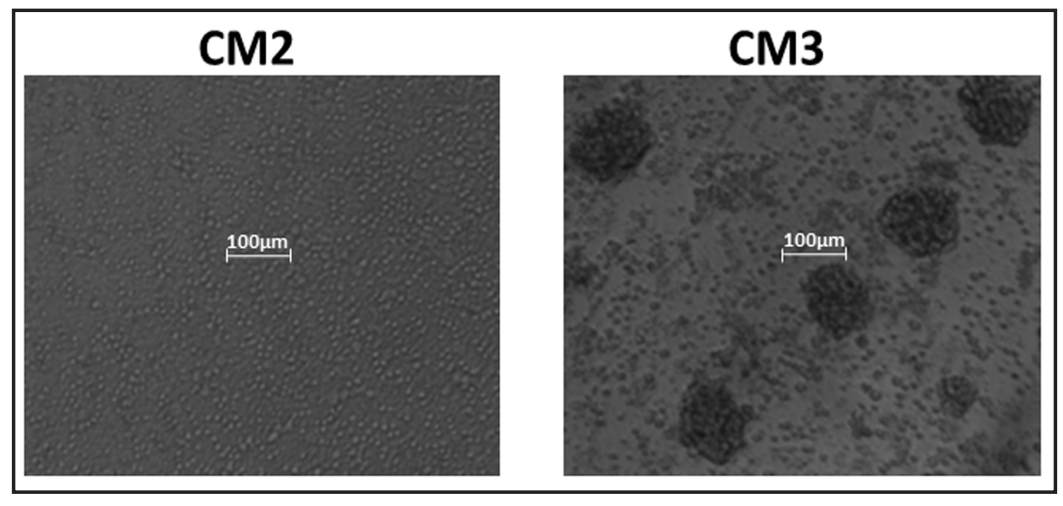
significantly increased numbers of colony-forming) compared with non-activated lymphocytes (absence of colony formation). C2C12, images were obtained at $20 \mathrm{x}$ magnification. 


\section{Culture of C2C12 myoblast}

Murine skeletal myoblasts purchased from ATCC (Rockville, MD, USA) were grown in T75 flasks in a humidified $5 \% \mathrm{CO}_{2}$ atmosphere at $37^{\circ} \mathrm{C}$ in growth medium (GM), composed of: DMEM media (Sigma, Poole, U.K) plus 10\% hiNCS, 10\% FBS (PAA Laboratories, Somerset, UK), and 1\% penicillin-streptomycin solution (Invitrogen, Paisley, UK), until 80\% confluence was attained. Following trypsinisation, adherent cells were detached and counted using a haemocytometer in the presence of trypan blue dye (Bio Whittaker, Wokingham, England) [20].

\section{C2C12 Treatments}

Six-well plates were pre-coated with $0.2 \%$ gelatine for $5 \mathrm{~min}$ at room temperature. Following removal of excess gelatine, C2C12 cells were seeded at $1 \times 10^{5}$ cells/ml in GM. On attaining approximately $80 \%$ confluency, cells were washed twice with PBS before culturing with the three different condition media; CM1, CM2 \& CM3. Following 15min, 36 \& 65 hrs of CM incubation, C2C12 were collected to perform the following the studies: Biochemical and morphological studies; cell cycle analysis, gene expression assay qRT-PCR, and cytometric bead arrays (CBA).

\section{Morphological Differentiation and FITC-Phallodin Staining}

Morphological parameters of differentiation, alignment, elongation, fusion and myotube formation were assessed using a cell imaging system at $20 \mathrm{X}$ magnification at $24,36,65 \& 96 \mathrm{hrs}$ post CM administration (Leica, DMI 6000 B, Milton Keynes, UK). Treated cells were fixed in 3.7\% formaldehyde solution and incubated at RT for 10 minutes. Cells were washed twice with PBS and permeabilised in $0.1 \%$ Triton-X-100 for 3 minutes. Following triton aspiration, Phalloidin-FITC ( $30 \mu \mathrm{g} / \mathrm{ml}$, Sigma Aldrich, Poole, UK) was added and incubated for $30 \mathrm{~min} / \mathrm{RT}$ before visualization using a fluorescent microscope as described above.

\section{Creatine Kinase (CK)}

Cells were treated as described above, washed twice with PBS and lysed in $0.2 \mathrm{ml}$ of $50 \mathrm{mM}$ TrisMES, pH 7.8, 1\% Triton X-100 (TMT buffer). CK assays were performed using a commercially available kit (Catachem, Oxford, UK) as previously described [21]. The absorbance activity of CK (differentiation marker) was measured at 3, 4 and 5 min post reaction initiation at a wavelength of $340 \mathrm{~nm}$ and changes in absorbance/min were calculated prior to normalisation against total protein content as determined by the $\mathrm{BCA}^{\mathrm{TM}}$ assay (Pierce, Rockford, IL, USA).

\section{Cell Cycle Analysis}

Flow cytomtery is widely used to determine the progression of cell cycle and cell population percentage in each stage of the cell cycle [22]. Cells were trypsinised and washed in PBS prior to fixing at $-20^{\circ} \mathrm{C}$ in $75 \%$ ethanol. After a minimum of $24 \mathrm{hrs}$, cells were washed twice in PBS and resuspended with gentle vortexing in propidium iodide labelling buffer $(50 \mathrm{mg} / \mathrm{ml}$ propidium iodide, $0.1 \%$ sodium citrate $20 \mathrm{mg} / \mathrm{ml}$ ribonuclease A, $0.3 \%$ Nonidet $\mathrm{P}-40, \mathrm{pH} 8.3$ ) at approximately $1 \times 10^{6}$ cells $/ \mathrm{ml}$. The cell events were acquired using Cell Quest software from FACSCalibur flow cytometer (Becton Dickinson, Oxford, England). Cell events and cell cycle phases were determined using ModFit ${ }^{\mathrm{TM}}$ software (Verity Software House, Topsham, ME).

\section{RNA Isolation and Gene Expression Assays}

Following cell treatments and incubations, conditioned medium was aspirated, cells were washed with PBS and lysed with $200 \mu \mathrm{l}$ TRIzol reagent. RNA was extracted from TRIzol homogenates according to the manufacturer's instructions (Invitrogen, CA) and 50 ng of RNA was used per reaction. TaqMan gene expression assays were performed for the target genes (MyoD and Myogenin) with the StepOnePlus system (Applied Biosystems, Foster City, CA). TaqMan ${ }^{\circledR}$ RNA-to-CT ${ }^{\mathrm{TM}}$ 1-Step Kit with standard TaqMan cycling conditions were used according to the manufacturer's instructions (Applied Biosystems, Foster City, CA) and all reactions were performed in triplicate. The housekeeping gene RNA polymerase II $\beta$ used as a reference gene (RPII $\beta$ ) which was performed in parallel as control with target genes [23] and gene expression levels were calculated using the comparative $2^{-\Delta \Delta \mathrm{Ct}}$ method where CM1 treated cells used as calibrator. 
Determination of $p$ ERK1/2 and pAkt phosphorylation level

$\mathrm{BD}^{\mathrm{TM}} \mathrm{CBA}$ is used to quantify multiple proteins, including intracellular phosphorylated signalling proteins, simultaneously. The specificity of the assay has been validated by immunoprecipitation and Western blotting to ensure that only the protein of interest are detected [24, 25]. CBA was performed as described previously [22]. Following $15 \mathrm{~min}$ of cell treatments, cells were washed at $4^{\circ} \mathrm{C}$ in PBS, lysed using lysis buffer $\left(1 \mathrm{x} \mathrm{BD}{ }^{\mathrm{TM}}\right)$ and denatured at $100^{\circ} \mathrm{C}$. To standardise $\mathrm{CBA}$, protein cell lysates were determined using $\mathrm{BCA}^{\mathrm{TM}}$ assay. Phospho-recombinant protein standards (ERK1/2, and Akt stock $5 \times 10^{4} \mathrm{Units} / \mathrm{ml}$ ) were prepared using serial doubling dilutions which was used to generate the standard curves. The relevant capture beads per phosphorylated protein were added to each sample. Following $2 \mathrm{~h}$ of incubation, PE detection reagent was added to each tube, followed by $1 \mathrm{~h}$ incubation. The samples were washed and centrifuged at 300x g for $5 \mathrm{~min}$. Cells were resuspended in $300 \mu \mathrm{l}$ of fresh wash buffer and analysed using Cell Quest Pro on a BD FACSCalibur. Three hundred events were captured per analyate per sample according to manufacturer's instructions. Data were filtered using FCS Filter ${ }^{\mathrm{TM}}$ and analysed using FCAP array software (Both programmes: Hungary Software Ltd., for BD Biosciences, San Jose, CA).

\section{Statistical Analysis}

All experiments were repeated three times independently in duplicate, unless otherwise stated and were analysed using GraphPad Prism software version 5.0. Results are presented as standard deviation (SD) of the mean. Statistical significance was determined using one-way ANOVA analysis followed by TukeyKramerith multiple post hoc analyses. Results were considered statistically significant when $\mathrm{P}<0.05$ against appropriate controls and marked with ${ }^{*}$ whereas ${ }^{* *}$ denotes $(\mathrm{P}<0.005)$, and ${ }^{* * *}$ denotes $(\mathrm{P}<0.001)$.

\section{Results}

In this study, two controls (CM1 \& CM2) were included to validate our findings and to exclude any effects of anti-CD3, IL-2 and RPMI-1640 media with $10 \%$ AB serum on C2C12 behaviour. In all the experiments, which were performed in the current study, we found that all the findings of these two controls were comparable and statistically non-significant. $\mathrm{C} 2 \mathrm{C} 12$ cultured in DM only was included in Figure 2 as internal control to indicate the normal progression of cells in the absence of any manipulation.

\section{Morphological and biochemical differentiation of myoblasts}

As the first step towards evaluating a potential interaction of the immune system on skeletal muscle maintenance, we morphologically assessed myoblasts treated with CM 1-3 (Fig. 2). CM3-treated C2C12 cells exhibit markedly reduced differentiation at 48, 65 and 96hrs, compared with controls CM1 and CM2. Under this condition (e.g. culture medium extracted following lymphocyte activation), cells maintained their reduced differentiation, mononuclear fibroblast-like morphology, with no myotube formation evident. Phallodin staining of C2C12 cells at $96 \mathrm{hrs}$ showed small, densely packed mononuclear cells in the presence of CM3 (Fig. 2 bottom right panel) whereas C2C12s cultivated in CM1 and CM2 clearly exhibit elongated, multi-nucleated myotube formation (Fig. 2 bottom left and central panels). These morphological findings were supported biochemically with CK activity assays (differentiation marker). CK activity increased significantly in C2C12 treated with CM1 and CM2 for 65 hrs $(300 \pm 46$; $p<0.001$, and 250 27 ; $<<0.005$, respectively) when compared with CK of myoblasts at the same timepoint, but treated with CM3 $(98 \pm 20$, Fig. 3A). These latter findings suggest growth arrest and fusion in CM1 and CM2, but continued growth in CM3. Indeed, these data were further supported by cell counting studies, which illustrated significantly reduced cell numbers in CM1 and CM2 treated $\left(70 \times 10^{4} \pm 3.8 \times 10^{4} ; \mathrm{p}<0.001\right.$, and $83 \times 10^{4} \pm 3.5 \times 10^{4} ; \mathrm{p}<0.001$ respectively), compared with $\mathrm{CM} 3$ treated $\mathrm{C} 2 \mathrm{C} 12$ cells $\left(146 \times 10^{4} \pm 12.5 \times 10^{4}\right.$, Fig 3B). 

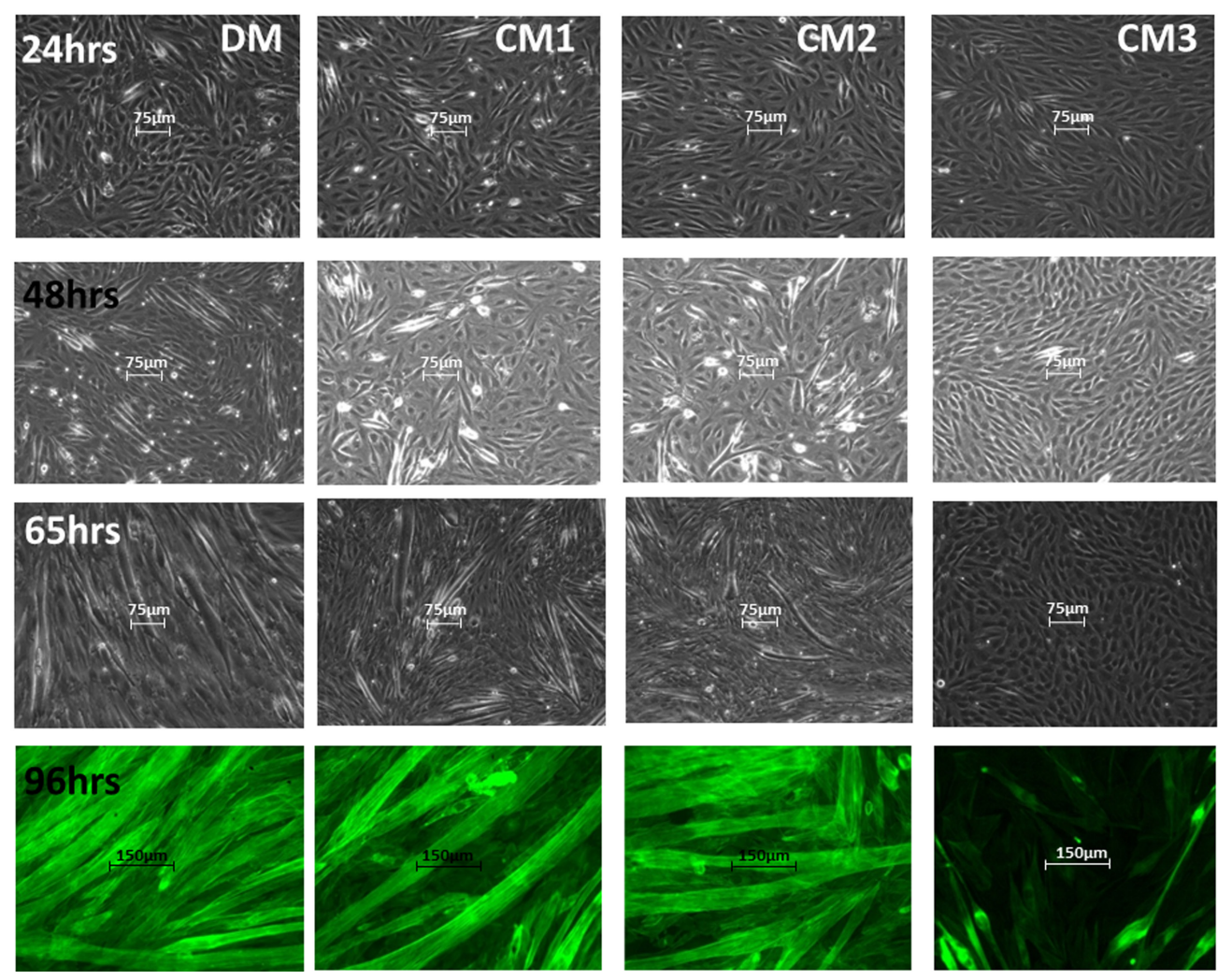

Fig. 2. Images of myoblasts differentiation and proliferation. Representative photographs of C2C12 myoblasts were treated either with CM1, CM2 or CM3 for 24, 48, 65 and 96hrs. DM represent C2C12 cultured with DM media only. (Images obtained at 20x magnification. Representative photomicrographs of C2C12 myoblasts stained with FITC-Phallodin (bottom panel), images obtained at 20x with 1.6 Mag.

\section{Cell cycle analysis}

G1 cell cycle arrest is a critical step for skeletal muscle cells to exit proliferation and commence differentiation. Flow cytometric cell cycle analyses are widely used to assess the proliferation of cultured cells. Such analyses confirmed cell cycle arrest in the C2C12 cells treated with CM1 and CM2, compared with CM3 treated cells. S-phase was $19 \% \pm 5(p<0.001)$ and $29 \% \pm 4.5(\mathrm{p}<0.005)$, respectively in CM1 and CM2 vs. $61 \% \pm 7$ in CM3 (Fig. 3C \& 3D).

\section{Gene Expression Analysis of MyoD and Myogenin}

The myogenic differentiation of myoblasts is controlled by the muscle-specific regulatory factors (MyoD and myogenin). To provide additional lines of evidence for the impact of activated immune cells on muscle proliferation with impeded differentiation, we wished to examine whether the mRNA expression levels of these myogenic factors were altered in the presence of CM3 vs CMs 1\&2. As shown in Figures 4A \& 4B, the expression levels of MyoD and myogenin in the $\mathrm{C} 2 \mathrm{C} 12$ cells cultured with CM1 and CM2 were not significantly different from each other. However, the expression levels of MyoD (Fig. 4A) and myogenin (Fig. 4B) in the cells treated with CM3 were significantly reduced to $0.5 \pm 0.12$ fold $(p<0.005)$ and $0.38 \pm 0.08$ fold $(\mathrm{p}<0.005)$ respectively; confirming the morphological data in Fig 4 above.

Determining signalling pathways phosphorylated proteins

Phosphorylated proteins acts as a molecular switches for many regulatory events that drive proliferation and differentiation of skeletal muscle cells [26]. Differentiation and 


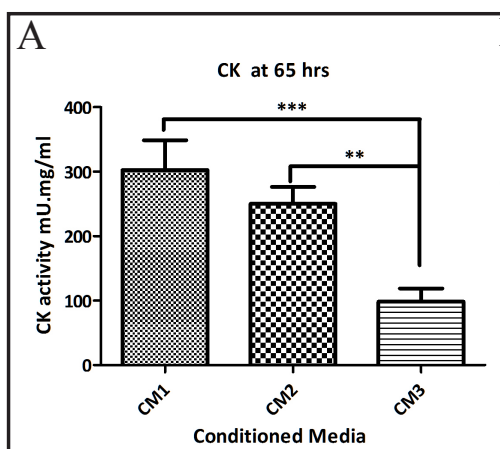

\section{$\mathrm{B}$}
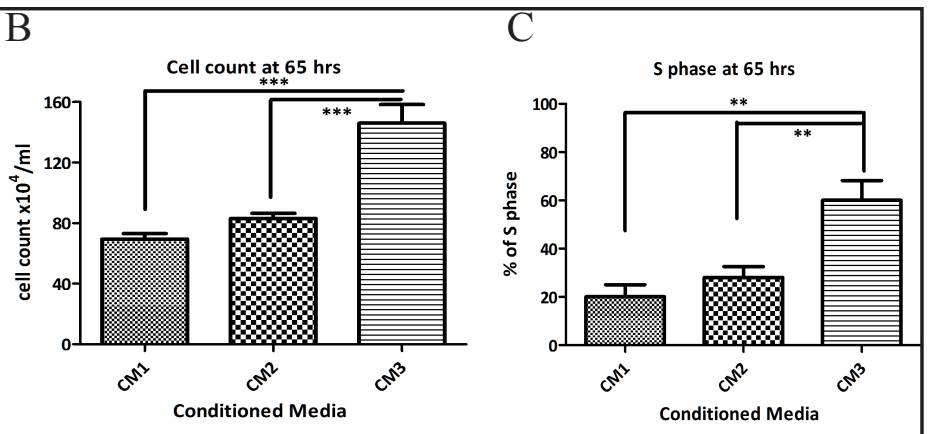

$\mathrm{D}$
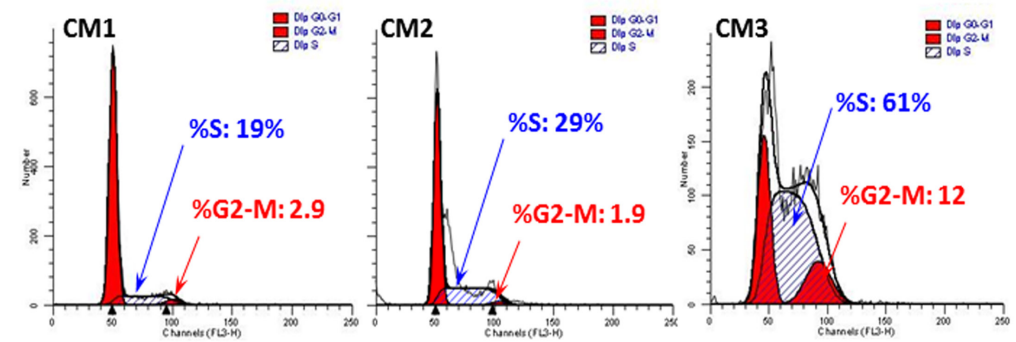

Fig. 3. Biochemical markers of myoblasts differentiation and proliferation. C2C12 $1 \times 10^{5} / \mathrm{ml}$ myoblasts were treated with CM1, CM2 and CM3 for 65 hrs where cells were collected for CK activity (A), for cell count (B), for cell cycle analysis (C). Representative photographs of C2C12 myoblasts cell cycle analysis (D). The bar graph represents the mean of the values obtained in three independent experiments. ${ }^{* *} P<0.005,{ }^{* * *} P<$ 0.001 vs controls.
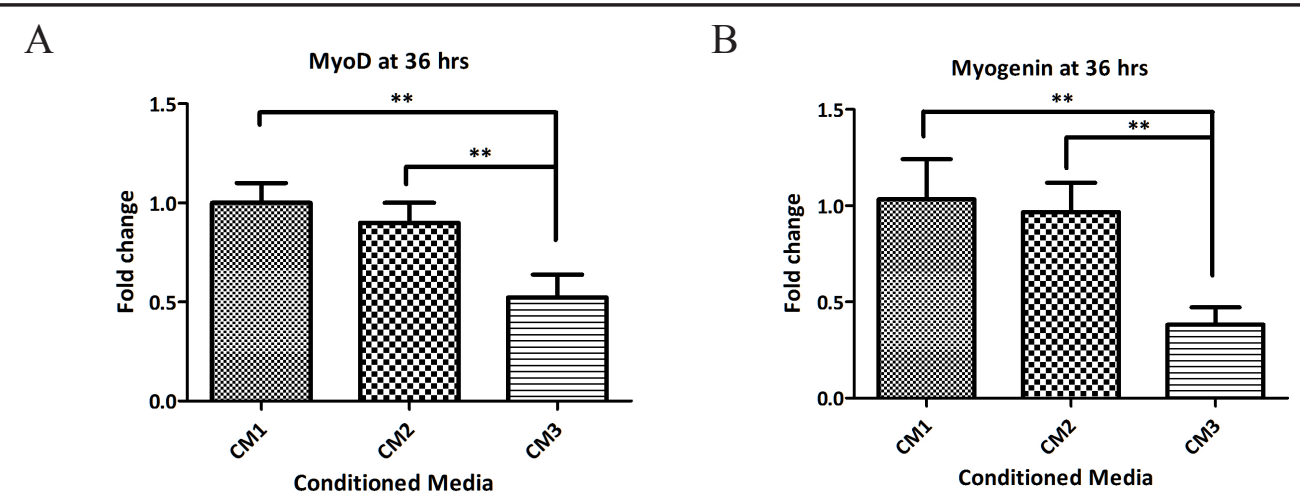

Fig. 4. Expression levels of mRNA of MyoD and Myogenin. C2C12 myoblasts were treated with CM1, CM2 and CM3 for 36hrs where cells were collected for gene expression assay. MyoD (A) and myogenin (B) mRNA expression levels were determined using $2^{-\Delta \Delta C \mathrm{~T}}$ and expressed as fold increase with respect to control. Results (means SD) are the means of three different experiments, ${ }^{* *} P<0.005$.

survival of myoblasts are regulated through the signalling pathways of PI3K/Akt whereas proliferation is controlled via Ras/ERK activation [27]. More recently, we have shown that while PI3K does control differentiation and ERK does control proliferation of muscle cells, both are actually required for successful differentiation $[28,29]$ to progress. To determine what role these kinases may play in this model, CBA arrays were employed to investigate how differentiation was enhanced in CM1/CM2 treated cells while proliferation was induced in CM3 treated cells. CM1 and CM2 treatment for 15 min significantly reduced the phosphorylation of pERK1/2 $(20 \pm 5 \mathrm{U} / \mathrm{ml} ; \mathrm{p}<0.05 \& 24 \pm 8.5 \mathrm{U} / \mathrm{ml} ; \mathrm{p}<0.05)$ respectively when compared to CM3 treated cells $(46 \pm 11 \mathrm{U} / \mathrm{ml}$, Fig. 5A). By contrast, pAkt phosphorylation 


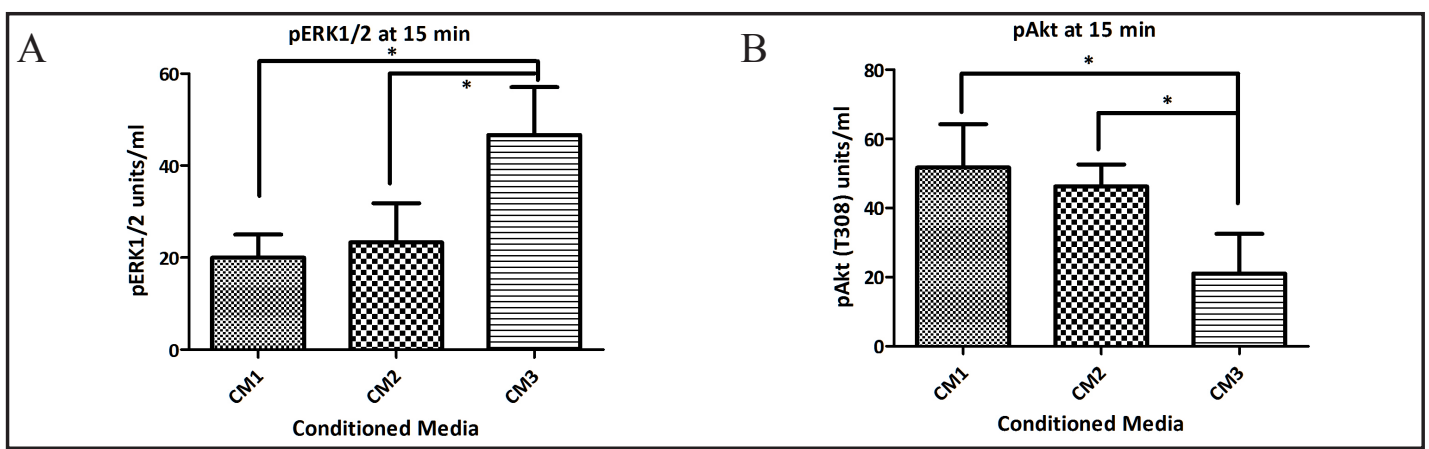

Fig. 5. Analysis of phospho-ERK1/2 and Akt protein levels in C2C12 myoblasts. C2C12 myoblasts were treated with CM1, CM2 and CM3 for 15 min where cells were collected for CBA ERK1/2 (A) and pAkt (B) assay. Samples are run against a standard curve which is generated using dilutions of a phosphorylated recombinant standard. The bar graph represents the mean of the values (units/ml) obtained in three independent experiments. ${ }^{*} P<0.05$ vs controls.

levels were significantly decreased $(21 \pm 12 \mathrm{U} / \mathrm{ml})$ in the presence of CM3 when compared with CM1 and CM2 (52 $\pm 13 \mathrm{U} / \mathrm{ml} ; \mathrm{p}<0.05$ and $46 \pm 6 \mathrm{U} / \mathrm{ml} ; \mathrm{p}<0.05)$ respectively (Fig. 5B). Once again confirming our morphological, biochemical and molecular analyses.

\section{Discussion}

As we age, not only do skeletal muscle system functions decline but the immune system also becomes impaired. The immune system responds to muscle damage with a complex sequence of immune reactions leading to recruitments of inflammatory and immune cells that ultimately lead to satellite cell activation, proliferation and eventually muscle regeneration. In the last decade, there has been a remarkable increase in the number of studies regarding the interaction of exercise and the immune system [10, 15, 30, 31]. However, a role of the acquired immune system, in particular T-lymphocytes, in muscle function and performance has not been investigated, but needs to be elucidated. Therefore, this study sought to investigate a possible interaction between human immune cells and murine skeletal muscle cells. Specifically, the ability of immune cell secretagogues to influence skeletal muscle cell proliferation and differentiation was determined. Adding human cytokines to murinederived cell lines could be a limitation of our current study, however, this model is greatly need to study human immune responses to pathogen infections in a small animal model in a systematic and controlled manner [32]. This model was recently used to investigate the effect of the inflammatory mediators secreted from A427 Human Lung [33] serum creatine phosphokinase in choline-deficient humans in C2C12 [34]. Moreover, it is well-established that many protein functions between humans and mice are conserved (similarities between mouse and human genes range from about $70 \%$ to $90 \%$ ) [35, 36]; these data therefore set the scene for future larger scale studies to investigate the impact of age and the immune system on muscle cell function in human samples in vitro.

To test our hypothesis, that lymphocytes, following activation (Fig. 1 using standard, published techniques [37]), will produce proteins, which influence muscle cell behaviour, we generated a carefully controlled Conditioned medium model to assess the interaction between activated lymphocytes and skeletal muscle myoblasts. Our data demonstrate that the control conditioned media (regardless of formulation) does not impact negatively on myoblast differentiation, thus providing excellent controls for the remainder of the study. Consistent with previous studies which reported that satellite cell-derived C2C12 myoblasts undergo spontaneous differentiation into myotubes in culture following serum withdrawal (differentiation media) $[38,39]$, we also showed that C2C12 cultured with CM1 and CM2 exhibit fusion of mononucleated myoblasts to form hypertrophic multinucleated myotubes. 
Interestingly, myoblasts cultured with CM3 were not able to differentiate, but rather exhibited high levels of proliferation. These significant findings were further supported with total cell counts and CK activity. Cell counting [40] and CK activity assessment [41] are widely used in myoblast research to confirm increased proliferation and differentiation, respectively. In agreement with these studies, our finding showed that CK activity was significantly increased in differentiating myoblasts (cells treated either with CM1 or with CM2). Moreover, cell counting indicated significantly increased proliferation in C2C12 cells treated with CM3, vs. C2C12 cells cultured with CM1 or CM2. Several studies have reported that cell cycle arrest is a critical step for myoblast differentiation to progress [42,43] whereas cell cycle progression leads to myoblast proliferation [43]. Consistent with these findings, our data demonstrated a significant increase in the number of $\mathrm{C} 2 \mathrm{C} 12$ myoblasts in S phase when treated with $\mathrm{CM} 3$ compared with $\mathrm{C} 2 \mathrm{C} 12$ cells treated with either CM1 or CM2.

We subsequently wished to establish the potential mechanisms underlying the negative impact of CM3 on myoblast differentiation. To this end, we next investigated the effect of CMs on the expression levels of muscle-specific transcription factors in our model [44, 45]. MyoD is a well-known marker of myogenic lineage, whereas myogenin, is a marker for the entry of myoblasts into the differentiation pathway [46]. In our study, gene expression levels were determined at 24, 48 (not shown), and 65hrs. No significant differences between the cells and treatments were evident at $24 \& 48 \mathrm{hrs}$. These observations are consistent with no apparent differences in morphology at this time point. Later in the differentiation process, however ( $65 \mathrm{hrs}$.), expression levels of both MyoD and myogenin were significantly reduced in CM3 treated vs.CM1 and CM2 cells. Again these observations were consistent with the morphological and the cell cycle findings, both of which indicated suppressed differentiation in CM3-treated cells.

To determine what signalling pathways may be functioning down stream of CM3 to block differentiation, CBA studies were performed following $15 \mathrm{~min}$ incubations with CMs 1-3. This time point was selected as previous studies in our laboratory indicated that maximal activation of these proteins (pERK1/2 and pAkt) was evident at this time [47]. In the current study, we demonstrated that pAkt and pERK1/2 were differentially elevated in the myoblasts treated with $\mathrm{CM} 1 / \mathrm{CM} 2$ and $\mathrm{CM} 3$ respectively. These findings are similar to those of studies in which pAkt expression levels were increased in differentiating myoblasts whereas pEKR1/2 levels were induced in proliferating C2C12 [22, 48, 49].

Taken together, our data suggest that there is an inhibitory interaction between proteins secreted by activated lymphocytes and skeletal muscle cell differentiation. This inhibition appears to occur as a consequence of increased ERK activity, decreased myoD and myogenin expression and ultimately enhanced proliferation of CM3-treated myoblasts. There are several hypotheses to explain our findings. One is that in vitro, anti-CD3 activated T-lymphocytes produce key interleukins (IL-10, IL-4, IL-6 and IL-7) and growth factors (Transforming growth factor- $\beta$; important in tissue repair, [50]) which may induce mitogenic responses of skeletal myoblasts [51]. It is well established that mitogens promote muscle cell proliferation but block differentiation [27, 52]. A second hypothesis would be that IGF-I, a key skeletal muscle cell growth factors, could be produced by activated lymphocytes [53-55] and this growth factor in combination with e.g. IL-6 may induce such effects [56]. Contradicting this proliferative role for IGF-I are numerous studies supporting a well-confirmed role for IGF in myoblast differentiation after serum withdrawal $[57,58]$. It is important to note, however, that the context of IGF-I and its subsequent impact on myoblast behaviour is critical, as we have shown in co-incubation studies using TNF \& IGF [59] and IL-6 \& IGF [56]. As a consequence of these initial, important observations, it is clear that a better understanding of the underlying mechanisms leading to such complex cellular outcomes is required. Future human studies investigating signalling pathways, genomic and proteomic adaptations, across the lifespan, need to be employed to identify and characterise which cytokines and downstream targets are important for manipulating myoblast behaviour and whether this outcome is influenced by the ageing process. It is ultimately a valid and important aim that results derived from studies on muscle-immune system interactions can be integrated into 
our understanding and hence manipulation of immunological processes in clinical medicine. Furthermore, results from the field of skeletal muscle immunology may influence the training programmes of elite athletes and contribute to public health recommendations on exercise for patients with chronic inflammatory diseases.

\section{Conclusion}

In summary, our findings uncovered a novel regulatory role for proteins secreted (secretome) by activated lymphocytes on myoblast differentiation and proliferation. These observations provide new insights into the complex cross-talk between the immune system and skeletal muscle cells, which may ultimately enable us to develop defined pharmaceutical interventions to attenuate the adverse effects of inflamed ageing.

\section{Conflict of Interests}

The authors declare that they have no conflict of interest.

\section{Acknowledgements}

Work was sponsored by the School of Healthcare Science, Faculty of Science and Engineering, John Dalton Building, Oxford Road, Manchester, UK.

\section{References}

$>_{2}$

$>3$

$>4$

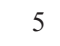

6

$>7$

$>_{8}$

$>9$

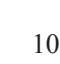

$>11$ Ann N Y Acad Sci 1998;854:78-91. 2007;113:461-487. Physiol Pharmacol 1998;76:469-472. use. Am J Pathol 2000;156:2103-2110.

Adibi SA: Metabolism of branched-chain amino acids in altered nutrition. Metabolism 1976;25:1287-1302. Lynch GS, Schertzer JD, Ryall JG: Therapeutic approaches for muscle wasting disorders. Pharmacol Ther

Rafi A, Castle SC, Uyemura K, Makinodan T: Immune dysfunction in the elderly and its reversal by antihistamines. Biomed Pharmacother 2003;57:246-250.

Tidball JG, Villalta SA: Regulatory interactions between muscle and the immune system during muscle regeneration. Am J Physiol Regul Integr Comp Physiol 2010;298:R1173-1187.

Malm C, Nyberg P, Engstrom M, Sjodin B, Lenkei R, Ekblom B, Lundberg I: Immunological changes in human skeletal muscle and blood after eccentric exercise and multiple biopsies. J Physiol 2000;529:243-262.

Pedersen BK, Toft AD: Effects of exercise on lymphocytes and cytokines. Br J Sports Med 2000;34:246-251. Shephard RJ, Shek PN: Immune responses to inflammation and trauma: A physical training model. Can J

Frenette J, Cai B, Tidball JG: Complement activation promotes muscle inflammation during modified muscle

Bondesen BA, Mills ST, Pavlath GK: The cox-2 pathway regulates growth of atrophied muscle via multiple mechanisms. Am J Physiol Cell Physiol 2006;290:C1651-1659.

Cheng M, Nguyen MH, Fantuzzi G, Koh TJ: Endogenous interferon-gamma is required for efficient skeletal muscle regeneration. Am J Physiol Cell Physiol 2008;294:C1183-1191.

Grounds MD: Age-associated changes in the response of skeletal muscle cells to exercise and regeneration. Cannon JG, St Pierre BA: Cytokines in exertion-induced skeletal muscle injury. Mol Cell Biochem 1998;179:159-167.

13 Tidball JG: Inflammatory cell response to acute muscle injury. Med Sci Sports Exerc 1995;27:1022-1032.

14 Farini A, Meregalli M, Belicchi M, Battistelli M, Parolini D, D'Antona G, Gavina M, Ottoboni L, Constantin G, Bottinelli R, Torrente Y: T and b lymphocyte depletion has a marked effect on the fibrosis of dystrophic skeletal muscles in the scid/mdx mouse. J Pathol 2007;213:229-238. 
Al-Shanti et al.: Lymphocytes Secretome Induces Myoblast Proliferation

15 Dumke BR, Lees SJ: Age-related impairment of t cell-induced skeletal muscle precursor cell function. Am J Physiol Cell Physiol 2011;300:C1226-1233.

16 Abe A, Koyama S, Ohtomo T, Kitamura N, Kaminuma O, Mori A: Murine t cell-derived contractile activity for bronchial smooth muscle cells. Int Arch Allergy Immunol 2012;158:7-10.

17 Al-Shanti N, Aldahoudi Z: Human purified cd8+ t cells: Ex vivo expansion model to generate a maximum yield of functional cytotoxic cells. Immunol Invest 2007;36:85-104.

18 Garland RJ, El-Shanti N, West SE, Hancock JP, Goulden NJ, Steward CG, Rowbottom AW: Human cd8+ ctl recognition and in vitro lysis of herpes simplex virus-infected cells by a non-mhc restricted mechanism. Scand J Immunol 2002;55:61-69.

19 Paul WE, Seder RA: Lymphocyte responses and cytokines. Cell 1994;76:241-251.

20 Saini A, Al-Shanti N, Sharples AP, Stewart CE: Sirtuin 1 regulates skeletal myoblast survival and enhances differentiation in the presence of resveratrol. Exp Physiol 2012;97:400-418.

21 Al-Shanti N, Faulkner SH, Saini A, Loram I, Stewart CE: A semi-automated programme for tracking myoblast migration following mechanical damage: Manipulation by chemical inhibitors. Cell Physiol Biochem 2011;27:625-636.

22 Al-Shanti N, Stewart CE: Inhibitory effects of il-6 on igf-1 activity in skeletal myoblasts could be mediated by the activation of socs-3. J Cell Biochem 2012;113:923-933.

23 Al-Shanti N, Saini A, Stewart CE: Two-step versus one-step rna-to-ct 2-step and one-step rna-to-ct 1-step: Validity, sensitivity, and efficiency. J Biomol Tech 2009;20:172-179.

24 Krutzik PO, Irish JM, Nolan GP, Perez OD: Analysis of protein phosphorylation and cellular signaling events by flow cytometry: Techniques and clinical applications. Clin Immunol 2004;110:206-221.

-25 Schubert R, Geiger H, Zielen S, Baer PC: Simultaneous detection of erk-, p38-, and jnk-mapk phosphorylation in human adipose-derived stem cells using the cytometric bead array technology. J Immunol Methods 2009;350:200-204.

-26 Haddad F, Adams GR: Inhibition of map/erk kinase prevents igf-i-induced hypertrophy in rat muscles. J Appl Physiol 2004;96:203-210.

27 Coolican SA, Samuel DS, Ewton DZ, McWade FJ, Florini JR: The mitogenic and myogenic actions of insulinlike growth factors utilize distinct signaling pathways. J Biol Chem 1997;272:6653-6662.

28 Foulstone EJ, Huser C, Crown AL, Holly JM, Stewart CE: Differential signalling mechanisms predisposing primary human skeletal muscle cells to altered proliferation and differentiation: Roles of igf-i and tnfalpha. Exp Cell Res 2004;294:223-235.

29 Saini A, Al-Shanti N, Stewart C: C2 skeletal myoblast survival, death, proliferation and differentiation: Regulation by adra1d. Cell Physiol Biochem 2010;25:253-262.

-30 Hawke TJ: T-cells and muscle just don't talk like they used to: Focus on "age-related impairment of $t$ cellinduced skeletal muscle precursor cell function". Am J Physiol Cell Physiol 2011;300:C1223-1225.

-31 Brunelli S, Rovere-Querini P: The immune system and the repair of skeletal muscle. Pharmacol Res 2008;58:117-121.

-32 Chen Q, Khoury M, Chen J: Expression of human cytokines dramatically improves reconstitution of specific human-blood lineage cells in humanized mice. Proc Natl Acad Sci U S A 2009;106:21783-21788.

- 33 Oraldi M, Maggiora M, Paiuzzi E, Canuto RA, Muzio G: Cla reduces inflammatory mediators from a427 human lung cancer cells and a427 conditioned medium promotes differentiation of c2c12 murine muscle cells. Lipids 2013;48:29-38.

-34 da Costa KA, Badea M, Fischer LM, Zeisel SH: Elevated serum creatine phosphokinase in choline-deficient humans: Mechanistic studies in c2c12 mouse myoblasts. Am J Clin Nutr 2004;80:163-170.

35 Boguski MS: Comparative genomics: The mouse that roared. Nature 2002;420:515-516.

-36 Suzuki Y, Yamashita R, Shirota M, Sakakibara Y, Chiba J, Mizushima-Sugano J, Nakai K, Sugano S: Sequence comparison of human and mouse genes reveals a homologous block structure in the promoter regions. Genome Res 2004;14:1711-1718.

37 Tsoukas CD, Landgraf B, Bentin J, Valentine M, Lotz M, Vaughan JH, Carson DA: Activation of resting t lymphocytes by anti-cd3 (t3) antibodies in the absence of monocytes. J Immunol 1985;135:1719-1723.

- 38 Blau HM, Pavlath GK, Hardeman EC, Chiu CP, Silberstein L, Webster SG, Miller SC, Webster C: Plasticity of the differentiated state. Science 1985;230:758-766.

-39 Sharples AP, Al-Shanti N, Stewart CE: C2 and c2c12 murine skeletal myoblast models of atrophic and hypertrophic potential: Relevance to disease and ageing? J Cell Physiol 2010;225:240-250. 
Al-Shanti et al.: Lymphocytes Secretome Induces Myoblast Proliferation

-40 Taylor WE, Bhasin S, Artaza J, Byhower F, Azam M, Willard DH Jr, Kull FC Jr, Gonzalez-Cadavid N: Myostatin inhibits cell proliferation and protein synthesis in c2c12 muscle cells. Am J Physiol Endocrinol Metab 2001;280:E221-228.

41 Meadows KA, Holly JM, Stewart CE: Tumor necrosis factor-alpha-induced apoptosis is associated with suppression of insulin-like growth factor binding protein-5 secretion in differentiating murine skeletal myoblasts. J Cell Physiol 2000;183:330-337.

42 Andres V, Walsh K: Myogenin expression, cell cycle withdrawal, and phenotypic differentiation are temporally separable events that precede cell fusion upon myogenesis. J Cell Biol 1996;132:657-666.

43 Moran JL, Li Y, Hill AA, Mounts WM, Miller CP: Gene expression changes during mouse skeletal myoblast differentiation revealed by transcriptional profiling. Physiol Genomics 2002;10:103-111.

-44 Zhu W, Boachie-Adjei O, Rawlins BA, Frenkel B, Boskey AL, Ivashkiv LB, Blobel CP: A novel regulatory role for stromal-derived factor-1 signaling in bone morphogenic protein-2 osteogenic differentiation of mesenchymal c2c12 cells. J Biol Chem 2007;282:18676-18685.

45 de la Serna IL, Roy K, Carlson KA, Imbalzano AN: Myod can induce cell cycle arrest but not muscle differentiation in the presence of dominant negative swi/snf chromatin remodeling enzymes. J Biol Chem 2001;276:41486-41491.

46 Knight JD, Kothary R: The myogenic kinome: Protein kinases critical to mammalian skeletal myogenesis. Skelet Muscle 2011;1:29.

47 Sharples AP, Al-Shanti N, Lewis MP, Stewart CE: Reduction of myoblast differentiation following multiple population doublings in mouse c2 c12 cells: A model to investigate ageing? J Cell Biochem 2011;112:37733785.

48 Creer A, Gallagher P, Slivka D, Jemiolo B, Fink W, Trappe S: Influence of muscle glycogen availability on erk1/2 and akt signaling after resistance exercise in human skeletal muscle. J Appl Physiol 2005;99:950956.

-49 Widegren U, Jiang XJ, Krook A, Chibalin AV, Bjornholm M, Tally M, Roth RA, Henriksson J, Wallberghenriksson H, Zierath JR: Divergent effects of exercise on metabolic and mitogenic signaling pathways in human skeletal muscle. Faseb J 1998;12:1379-1389.

50 Ohtsuka K, Gray JD, Stimmler MM, Toro B, Horwitz DA: Decreased production of tgf-beta by lymphocytes from patients with systemic lupus erythematosus. J Immunol 1998;160:2539-2545.

51 Pinderski LJ, Fischbein MP, Subbanagounder G, Fishbein MC, Kubo N, Cheroutre H, Curtiss LK, Berliner JA, Boisvert WA: Overexpression of interleukin-10 by activated tymphocytes inhibits atherosclerosis in ldl receptor-deficient mice by altering lymphocyte and macrophage phenotypes. Circ Res 2002;90:1064-1071.

-52 Porras A, Alvarez AM, Valladares A, Benito M: P42/p44 mitogen-activated protein kinases activation is required for the insulin-like growth factor-i/insulin induced proliferation, but inhibits differentiation, in rat fetal brown adipocytes. Mol Endocrinol 1998;12:825-834.

53 Merchav S, Tatarsky I, Hochberg Z: Enhancement of human granulopoiesis in vitro by biosynthetic insulinlike growth factor i/somatomedin c and human growth hormone. J Clin Invest 1988;81:791-797.

54 Aron DC: Insulin-like growth factor i and erythropoiesis. Biofactors 1992;3:211-216.

55 Leng SX, Hung W, Cappola AR, Yu Q, Xue QL, Fried LP: White blood cell counts, insulin-like growth factor-1 levels, and frailty in community-dwelling older women. J Gerontol A Biol Sci Med Sci 2009;64:499-502.

56 Al-Shanti N, Saini A, Faulkner SH, Stewart CE: Beneficial synergistic interactions of tnf-alpha and il-6 in c2 skeletal myoblasts--potential cross-talk with igf system. Growth Factors 2008;26:61-73.

57 Rommel C, Bodine SC, Clarke BA, Rossman R, Nunez L, Stitt TN, Yancopoulos GD, Glass DJ: Mediation of igf1-induced skeletal myotube hypertrophy by pi(3)k/akt/mtor and pi(3)k/akt/gsk3 pathways. Nat Cell Biol 2001;3:1009-1013.

-58 Stewart CE, Rotwein P: Growth, differentiation, and survival: Multiple physiological functions for insulinlike growth factors. Physiol Rev 1996;76:1005-1026.

-59 Saini A, Al-Shanti N, Faulkner SH, Stewart CE: Pro- and anti-apoptotic roles for igf-i in tnf-alpha-induced apoptosis: A map kinase mediated mechanism. Growth factors 2008;26:239-253. 